\title{
Stormwater Pond Management: What You Need to Know about Aeration'
}

\author{
Samantha T. Howley, Steven P. Hohman, and Alexander J. Reisinger ${ }^{2}$
}

\section{Introduction}

As Floridians, we are familiar with stormwater ponds and their associated fountains. There are at least 75,000 stormwater ponds across our state (Sinclair et al. 2020), and they can be found anywhere, from our neighborhood to our favorite golf course or the strip mall where we buy groceries. While you have undoubtedly seen plenty of stormwater ponds, you might not know much about how they work. Stormwater ponds are not just decorations to increase property value or improve aesthetics; they play an integral role in protecting the local watershed from the negative impacts of urbanization. Stormwater ponds' primary purpose is flood control, and they are designed to intercept stormwater runoff (precipitation that runs off our buildings, roads, parking lots, and sidewalks), but they also provide other services like a place for sediment to settle out of the water column, habitat for wildlife, recreational opportunities like birding, and pollutant removal. Overall, stormwater ponds help mitigate the impacts of urban stormwater runoff while protecting our natural waterways from nutrient loading, erosion, sedimentation, and algal blooms.

This document is intended to provide Floridians and their communities with information on a specific management practice in stormwater ponds: the use of fountains and other aeration approaches. These practices may provide opportunities both to improve water quality within the pond and protect downstream water quality. Specifically, this document gives basic information on fountains and the pros and cons of fountain (and other aeration device) installation and use. In addition, we provide information for pond managers or community decision makers on how to best manage ponds for effective pollutant removal in the pond and downstream water quality protection. This document does not provide a technical guide for selecting/ designing aeration practices for ponds; rather, it provides an overview for how aerators, such as fountains, may affect water quality within stormwater ponds.

\section{Stormwater Ponds}

When living in a state that experiences fifty inches (or more) of rain a year, flooding is a constant threat. Without proper management, the water that runs off the landscape during a storm (stormwater) can transport pollutants such as sediments, heavy metals, pesticides, organic pollutants, and nutrients into natural waterways or artificial canals, impacting water quality and biodiversity, leading to algal blooms, or leading to aesthetic/odor concerns. Additionally, flooding has the potential to erode infrastructure, cause property damage, and promote stream incision when higher-than-normal flow rates erode stream banks. With Florida's highly urbanized landscape and the population growing by roughly 900 people per day, flooding from stormwater poses an increasingly substantial risk.

1. This document is SL482, one of a series of the Department of Soil and Water Sciences, UF/IFAS Extension. Original publication date January 2021. Visit the EDIS website at https://edis.ifas.ufl.edu for the currently supported version of this publication.

2. Samantha T. Howley, former undergraduate student, Environmental Science Program within the School of Natural Resources and Environment; Steven P. Hohman, former graduate student; and Alexander J. Reisinger, assistant professor, Department of Soil and Water Sciences; UF/IFAS Extension, Gainesville, FL 32611.

The Institute of Food and Agricultural Sciences (IFAS) is an Equal Opportunity Institution authorized to provide research, educational information and other services

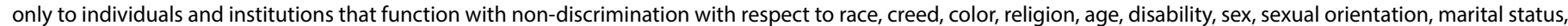

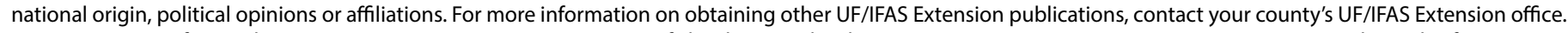
U.S. Department of Agriculture, UF/IFAS Extension Service, University of Florida, IFAS, Florida A \& M University Cooperative Extension Program, and Boards of County Commissioners Cooperating. Nick T. Place, dean for UF/IFAS Extension. 
Stormwater ponds are designed to mitigate flooding by catching excessive precipitation running off our buildings, roads, parking lots, sidewalks, and any other impervious surfaces (land cover that stops water from infiltrating into the soil, such as stormwater or excess water irrigating a lawn) that could cause water to flood our homes or streets. Instead of rapidly running off, stormwater ponds slow this water down and either allow it to percolate into the ground or simply reduce the rate of runoff into downstream water bodies. Stormwater ponds are defined as either retention or detention ponds. In Florida, dry stormwater ponds and swales are dry for most of the year but become inundated after rain events. Wet stormwater ponds are typically inundated year-round. Retention ponds keep all water within them and prevent it from moving downstream. Dry retention ponds typically allow water to infiltrate into the soil. In contrast, detention ponds capture stormwater runoff and temporarily store it before slowly releasing the water downstream. This can be thought of as the difference between getting detention in school, where you have to stay back for a short time and are then sent home, versus getting retained in the 7th grade. Regardless of the retention/ detention design, stormwater ponds mitigate downstream flooding while also providing additional water quality benefits via natural pollutant removal processes.

Natural processes within an aquatic ecosystem can remove various pollutants, such as nitrogen and phosphorus, via plant uptake or microbial transformations. These natural processes represent temporary (vegetation and certain microbial processes) or permanent (specific microbial processes) removal of nutrients and pollutants from the water column, reducing potential impacts on downstream ecosystems. For instance, vegetation requires nutrients for growth, and therefore plants can act as a filter to remove nutrients from the water column. However, this is only a temporary solution as vegetation will eventually die and decay, returning any stored nutrients back to the water. In contrast, denitrification is a natural microbial process that occurs within pond sediments, providing a permanent removal of nitrate from the water column (for more on the nitrogen cycle, see https://edis.ifas.ufl.edu/ss641). When coupled together, permanent and temporary processes of nutrient removal can reduce eutrophication, an increase in primary production (from plants or algae) typically caused by an accumulation of nutrients (naturally or via human inputs like fertilizer, grass clippings, and pet waste). Eutrophication can result in hypoxia (low oxygen concentrations in the water column) via decomposition of algae or an abundance of respiration by plants and animals. For more information on eutrophication, visit https://edis.ifas.ufl. $\mathrm{edu} / \operatorname{sg} 118$.

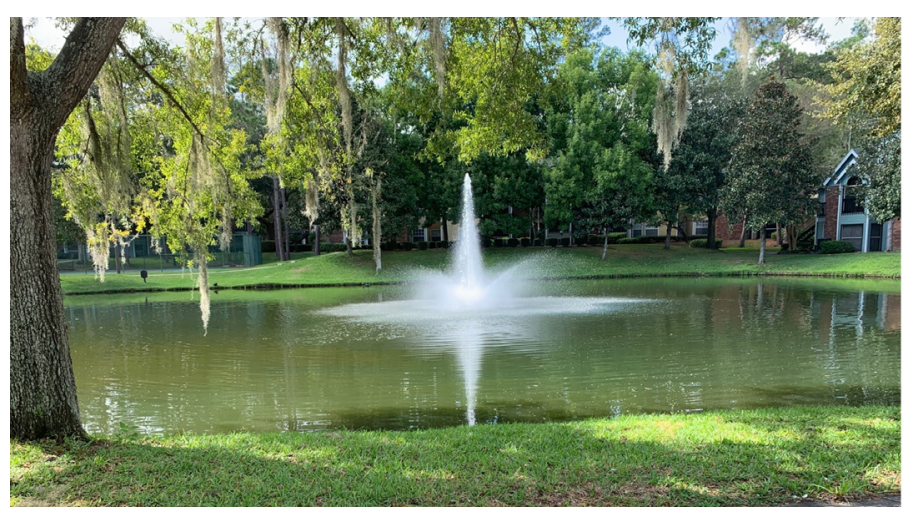

Figure 1. A stormwater pond in a residential neighborhood in Gainesville, FL. This fountain provides important functions to the pond while also providing aesthetic benefits. Credits: Samantha Howley, UF/IFAS

\section{Benefits of Fountains or Other Aeration Devices}

Stormwater ponds are helpful in mitigating downstream environmental impacts, but due to conditions like sedimentation, stratification (see below), and hypoxia (see below), stormwater ponds can exhibit varying effectiveness.

One method to maintain acceptable water quality within a pond, while still protecting downstream water quality, is the installation of an aerator. Water becomes oxygenated when it comes in contact with the atmosphere, and therefore, water exposed to the air at the surface of a pond typically has a higher dissolved-oxygen (DO) concentration than the water at greater depths. Having DO in the water is important because it allows for aquatic organisms, like fish or tadpoles, to breathe, and it also aids in nutrient removal processes. Aeration devices can increase DO by circulating air, water, or both throughout the pond, increasing mixing of the water and the interaction between the water and the atmosphere. There are a variety of approaches to aeration, but common aeration systems include fountains (surface aerators) and bubblers (diffusers or bottom aerators). Fountains, which float at the surface while anchored to the bottom, typically draw surface water into a pump and then spray the water into the air (Figure 1). This increases the interaction between pond water and the atmosphere, increasing the amount of oxygen in the pond water. Additionally, the force of the moving water can create waves at the surface of the pond that can disrupt algal scums. In contrast to fountains, bubblers consist of a blower (similar to an air compressor) on the pond bank, a weighted airline, and one of more diffusers (located at the bottom of the pond) and draw air from the atmosphere and release it through the diffusers as bubbles into the water column (Figure 2). As the bubbles rise to the surface, the oxygen in the bubbles diffuse into the low-DO bottom waters, while 
bringing oxygen-poor water with them to the pond surface. Fountains expose water to the atmosphere in long sprays, while bubblers create bubbles and ripples at the surface. Either fountains or blowers can enhance aeration and mixing of a pond, with fountains typically recommended for shallow ponds, whereas bubblers are more effective in deeper ponds.

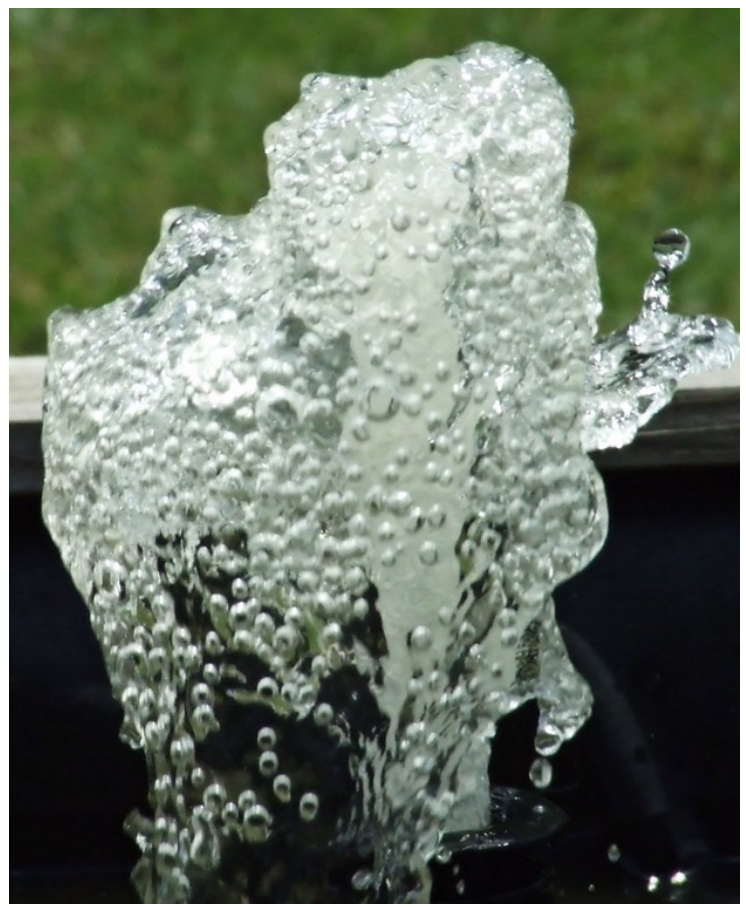

Figure 2. A bottom aerator, also known as a bubbler, propels air collected from a blower located on the pond shore or bank through diffusers. Bubbles can optimize pond function, especially for ponds greater than eight feet in depth.

Credits: "FOUNTAIN tsg" by carl \& tracy gossett, licensed under CC BY-ND 2.0. Original image available at https://www.flickr.com/ photos/24957796@N05/2562243164

\section{Turbidity}

A fountain's ability to create disturbances in the pond's water column by means of spraying water into the air may affect the turbidity of a pond. Turbidity is a measure of how transparent water is given the presence of suspended material, such as suspended sediment and algae. Having low turbidity means the water is clear, and light is able to reach the bottom of the pond, whereas high turbidity means light does not penetrate as far into the water, potentially limiting the ability of a pond to sustain plant life below the surface.

Algae are photosynthetic organisms that resemble plants but lack roots, stems, or leaves. Algae are classified as either macroalgae, multicellular aquatic plant-like organisms (such as Nitella or Chara), or microalgae, small, often unicellular, photosynthetic organisms. Having microalgae in the water column increases pond turbidity and can give rise to other water quality concerns.
The word "algae" has almost become a dirty word in Florida, because it has many negative connotations. But algae are not "good" or "bad." In the right concentrations, algae are an important part of a natural, functioning aquatic ecosystem. Algae are a food source for animals, can absorb excess nutrients from the water, and produce oxygen via photosynthesis. However, when free-floating algae (phytoplankton) grow to excess (Figure 3), they can block the sunlight from reaching submersed vegetation and can lead to low DO conditions, which can result in a fish kill (see below). Furthermore, some species of algae or cyanobacteria (blue-green algae) can cause algal blooms that produce toxins that can be harmful to humans or wildlife. Toxin-producing algal blooms are commonly referred to as harmful algal blooms. For more information, refer to the EDIS topic area on harmful algal blooms, available at https://edis.ifas.ufl.edu/topic_harmful_algal_blooms.

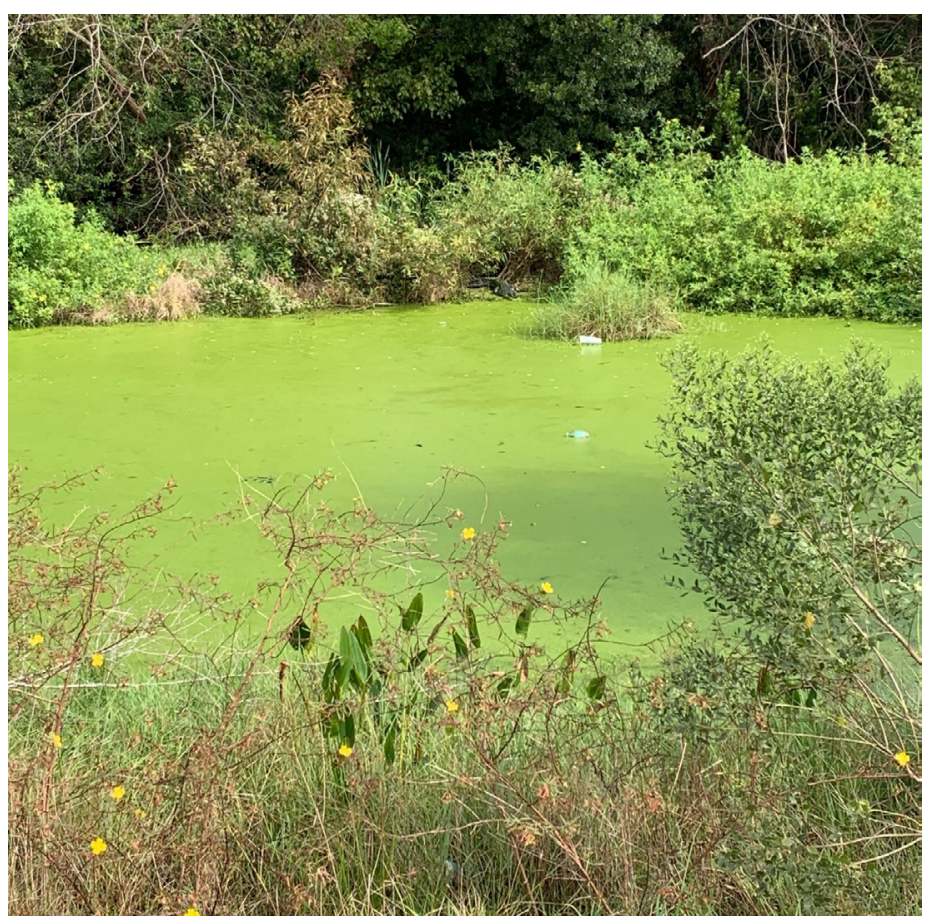

Figure 3. A eutrophic pond with stagnant water. This pond is likely highly stratified with low dissolved oxygen in the bottom waters. Credits: Samantha Howley, UF/IFAS

Stormwater ponds are ideal locations for algal blooms. The nutrient conditions within stormwater ponds are particularly good for algal growth, because stormwater ponds are constructed to receive nutrients (nitrogen and phosphorus) from various sources in urban areas, including fertilizers, reclaimed water used for irrigation, plant material (e.g., grass clippings, leaves), or pet waste. There are also natural nutrient sources, such as phosphorus-rich soils. Certain cyanobacterial species can actually obtain nitrogen from the air to grow. For more information on urban nutrient sources, see EDIS publication SL468, Sources and 
Transformations of Nitrogen in Urban Landscapes, available at https://edis.ifas.ufl.edu/ss681.

By inhibiting algal growth, fountains can reduce turbidity, but in some ponds, fountains or bubblers can actually increase turbidity (reduce water clarity) by resuspending sediment from the bottom of the pond or forcing particles to remain in suspension in the water column. When sediment and other particles enter a water body, the sediment is denser than the water and will eventually settle to the bottom of the waterbody. In a fountain pond, the forceful mixing may prevent sediments from sinking to the bottom. Instead, sediment can remain suspended in the water column, impeding clarity.

\section{Hypoxia}

Dissolved oxygen (DO) is the amount of oxygen in water that is readily available to aquatic life. Just like humans, aquatic organisms, such as fish, tadpoles, or crayfish, require oxygen for life. Hypoxia and anoxia are terms used to describe a water body with low (hypoxic) or no (anoxic) oxygen in the water. If the water column becomes hypoxic (DO concentrations $<2-3 \mathrm{mg} / \mathrm{L}$ ), aquatic organisms typically cannot survive, and a die-off can occur. In Florida, we are no stranger to eutrophic and hypoxic conditions, and massive fish kills are not uncommon. For more information on fish kills, see the EDIS publication A Beginner's Guide to Water Management_Fish Kills, available at https://edis.ifas. ufl.edu/fa104.

Hypoxia, especially in Florida, tends to occur in eutrophic water bodies. Both photosynthesis (which produces oxygen) and respiration (the use of oxygen by organisms, including algae and submersed aquatic vegetation) occur within aquatic ecosystems. While photosynthesis only occurs during the day, respiration is constantly occurring, day and night. As algae bloom, not only does the amount of photosynthesis increase, but respiration also increases. This can lead to large changes in dissolved oxygen between the day and night. Furthermore, on cloudy days, algae produce less oxygen due to reduced sunlight (which is needed for photosynthesis), but respiration still occurs. Therefore, in ponds with a lot of algae, dissolved oxygen can reach hypoxic or anoxic conditions in the early morning around sunrise or after several days of calm, cloudy, hot weather. In addition, algae die every day, but under the proper conditions a massive algal die-off can occur. As these decaying algae decompose, oxygen is consumed, which can cause hypoxic or anoxic conditions to form.

\section{Stratification}

Stratification is when a pond or lake develops different layers of water and these different layers do not mix (Figure 4). As sunlight hits a pond, the surface waters heat up. The density of water decreases with increasing water temperature, so as the water warms on the surface, it becomes less dense. This warmer, less dense water "floats" on top of the colder, denser, deeper water. If waters are calm, this density gradient will continue to build, eventually causing discrete layers of surface and bottom waters to form. If you've ever jumped into a lake on a hot summer day and noticed that the water is significantly colder in deeper parts of the lake, you've experienced stratification.
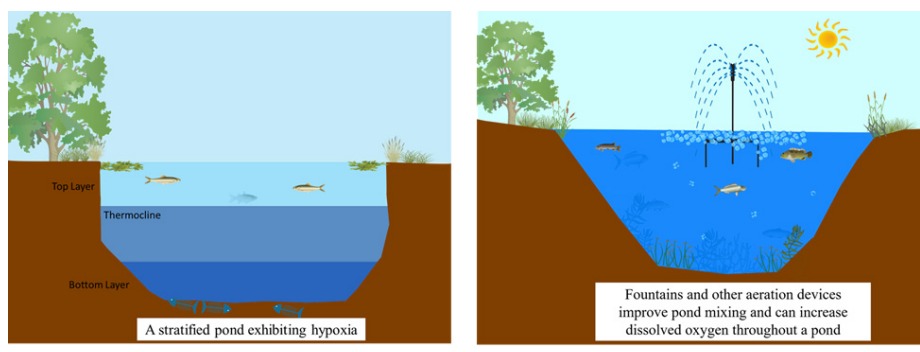

Figure 4. Stratified ponds (left) exhibit different layers that prevent water from mixing, potentially leading to hypoxia in bottom waters. Fountains and bubblers (right) can reduce hypoxia in deeper water by increasing oxygen in a pond while also physically mixing pond waters to reduce stratification. Bubblers are more effective at aerating a deep pond, whereas fountains provide additional oxygen near the pond surface.

Credits: Samantha Howley, UF/IFAS

However, once these layers have formed, water (and anything dissolved in it) does not mix across the layer boundaries, effectively isolating the bottom water from the atmosphere, potentially leading to hypoxia in the bottom layer. Like oil and water, these layers will need an outside force to mix them, such as strong wind. Without an outside force, water at the surface will remain oxygenated through photosynthesis and diffusion from the atmosphere, but none of this oxygen penetrates into the deeper, colder water. Dead algae, leaves, and other organic matter will sink into the deeper water. Bacteria in the deeper water will further decrease DO as they decompose the organic matter.

Fountains, bubblers, and other aerators can physically mix a pond by pumping below-surface water into the air and spraying it across the surface of the pond (fountain) or injecting air bubbles into the bottom of a pond, which will then rise and disrupt stratification layers (bubblers). This allows nutrients, oxygen, and water to circulate throughout the pond. A fountain may reduce the likelihood of stratification (Figure 4), but bubblers are more efficient at mixing ponds with depths of eight feet or greater because they force air to move throughout the entire water column, whereas 
fountains primarily interact with the upper portions of the pond. Fountains are unlikely to fully mix and de-stratify deep ponds.

\section{Fountain and Other Aerator Cons}

Although fountains are a helpful tool in minimizing hypoxia and stratification within a pond, they have drawbacks. Fountains can increase bank erosion (Figure 1). Similar to beach erosion, the constant wave action that fountains cause can increase shoreline erosion, especially for ponds without a vegetation buffer around the perimeter of the pond. In extreme circumstances, this can cause property damage, increased sedimentation into the pond, and dangerous, steep inclines on the pond's edge. This increased sedimentation will reduce the volume of a pond, requiring costly dredging to ensure that the pond is capable of storing the necessary volume of stormwater runoff for which it was designed. To minimize bank erosion and sedimentation, ensure that the correct size fountain relative to the pond's volume and head height (the height of the ejected water from the surface) is used.

There are many types of aeration devices, and selection and installation will depend on the need for aeration, as well as the pond manager's aesthetic desires. Fountains are typically not recommended for aeration purposes in ponds deeper than approximately eight feet. For deeper ponds, bottom diffusers (bubblers) will provide greater water quality benefits (US EPA 2009). Availability and location of electricity to power the aerators must also be considered. However, the aesthetic benefits of a fountain are also important. If fountains are selected, planting ornamental plants along the banks is one approach to reduce bank erosion of the ponds. For more information on things to consider when selecting plants to install on the edges of stormwater ponds, see the EDIS document $A$ New Database on Trait-Based Selection of Stormwater Pond Plants, available at https://edis.ifas.ufl.edu/fr416.

While fountains and bubblers may reduce the likelihood of stratification and hypoxia if they are functioning properly, they do not guarantee that a natural fish kill won't occur. Under certain conditions, the initial installation and operation of aeration devices can actually induce a short-term hypoxic event and cause a fish kill. This occurs when a pond is highly stratified, with extremely low oxygen concentrations in the bottom layers of the water and oxygenated surface waters where the aquatic life resides. After fountain installation, if these layers are mixed too rapidly, the low-oxygen bottom waters will mix with the oxygenated surface water, potentially making the entire pond hypoxic for a period of time. Further, nutrient-rich bottom waters mixing with surface waters could stimulate algal growth and lead to an algal bloom. To avoid a possible fish kill or algal bloom, aerators should be installed and begin operation in the winter or early spring, when the water is cooler and ponds are generally not stratified, or following a storm event, which will naturally mix a pond. If a pond is stratified, fountains should be operated for brief periods of time, increasing the hours of operation as the pond becomes more mixed. The bubbler diffusers could be installed at a shallower depth and then slowly lowered into the pond over an extended period of time (one foot per week [USA EPA 2009]). Dissolved oxygen should be monitored closely during this initial period to ensure hypoxia is not accidentally induced.

An additional consideration for whether a fountain or other aeration device is right for your pond is the cost of the aerator itself. Depending on the size and purpose, a fountain can cost hundreds to thousands of dollars, not including the installation fee or the maintenance they require. Furthermore, electricity is needed to power the aerator, increasing initial and maintenance expenses (although fountains can often be powered by solar electricity). It is up to each property owner's discretion whether the consequences outweigh the potential benefits.

\section{Sources}

Clemson Cooperative Extension. n.d. "Aeration, Circulation, and Fountains." https://www.clemson.edu/extension/ water/stormwater-ponds/problem-solving/aerationcirculation/index.html

Hill, P. 2013. "Pros and Cons of Surface Aeration in Wastewater Lagoons." Blog post. http://www.triplepointwater. $\mathrm{com} /$ pros-and-cons-of-surface-aeration-in-wastewaterlagoons/\#.Xmeu_pNKit8

Lake Carmi Implementation Team. 2018. "Pros and Cons of Whole-Lake Aeration." Vermont DEC Presentation. https://dec.vermont.gov/sites/dec/files/wsm/lakes/docs/ lp_LakeCarmi_ProsConsAeration_2018-10-18.pdf

Scramlin, J., S. Wesorick, R. Kendrick, K. Kaplan, and S. Cotton. n.d. "Visual Encyclopedia of Chemical Engineering: Aerators." http://encyclopedia.che.engin.umich.edu/ Pages/TransportStorage/Aerators/Aerators.html 
Sinclair, J. S., A. J. Reisinger, E. Bean, C. R. Adams, L. S.

Reisinger, and B. V. Iannone. 2020. "Stormwater Ponds:

An Overlooked but Plentiful Designer Ecosystem Provides

Invasive Plant Habitat in a Subtropical Region (Florida,

USA)." Science of the Total Environment 711:135133. https://

doi.org/10.1016/j.scitotenv.2019.135133

United States Environmental Protection Agency. 2009.

Stormwater Wet Pond and Wetland Management Guidebook.

EPA Publication 833-B-09-001. https://www3.epa.gov/

npdes/pubs/pondmgmtguide.pdf 